\title{
$\begin{array}{ll}\text { Research Square } & \text { Preprints are preliminary reports that have not undergone peer review. } \\ \text { They should not be considered conclusive, used to inform clinical practice, }\end{array}$
}

\section{High frequency of benzimidazole resistance alleles in trichostrongyloids from Austrian sheep flocks in an alpine transhumance management system}

\author{
Barbara Hinney ( $D$ Barbara.Hinney@vetmeduni.ac.at) \\ Institute for Parasitology https://orcid.org/0000-0001-7757-1002 \\ Julia Schoiswohl \\ Veterinarmedizinische Universitat Wien \\ Lynsey Melville \\ Moredun Research Institute \\ Vahel J. Ameen \\ Faculty of Veterinary Medicine, University of Duhok \\ Walpurga Wille-Piazzai \\ Veterinarmedizinische Universitat Wien \\ Karl Bauer \\ TGD Steiermark \\ Anja Joachim \\ Veterinarmedizinische Universitat Wien \\ Jürgen Krücken \\ Fu Berlin, Insitut für Parasitologie und Tropenveterinärmedizin \\ Philip J. Skuce \\ Moredun Research Institute \\ Reinhild Krametter-Frötscher \\ Veterinarmedizinische Universitat Wien
}

Research article

Keywords: nematode, anthelmintic resistance, single nucleotide polymorphism, trichostrongyloids, pyrosequencing

Posted Date: April 2nd, 2020

DOI: https://doi.org/10.21203/rs.2.18014/v2

License: (c) (i) This work is licensed under a Creative Commons Attribution 4.0 International License. Read Full License

Version of Record: A version of this preprint was published at BMC Veterinary Research on May 11th, 2020. See the published version at https://doi.org/10.1186/s12917-020-02353-z. 


\section{Abstract}

Background: Infections of small ruminants with trichostrongyloid nematodes often result in reduced productivity and may be detrimental to the host. Anthelmintic resistance (AR) against most anthelmintic drug classes is now widespread amongst the trichostrongyloids. Baseline establishment, followed by regular monitoring of the level of AR, is necessary for farmers and veterinarians to make informed decisions about parasite management. The detection of single nucleotide polymorphisms (SNPs) is a sensitive method to detect AR against benzimidazoles (BZs), one of the most widely used anthelmintic classes. Alpine transhumance constitutes a special type of pasturing of sheep from many different farms, the aim of this study was to investigate the prevalence of benzimidazole resistance alleles in this particular management system.

Results: Sixteen sheep flocks in Styria and Salzburg in Austria were examined by pyrosequencing for SNPs at codons 167,198 and 200 of the isotype- $1 \beta$-tubulin gene. The frequency of the resistance-associated exchange F200Y was $87-100 \%$ for $\mathrm{H}$. contortus, $77-100 \%$ for T. colubriformis and $<5-66 \%$ for T. circumcincta. Additionally, the F167Y polymorphism was detected in T. colubriformis from two farms at a frequency of $19 \%$ and $23 \%$ respectively.

Conclusions: The high resistance allele frequency in $H$. contortus and $T$. colubriformis in the examined sheep population urgently calls for the development of new treatment strategies to sustainably control trichostrongyloid infections for this kind of pasturing, since the frequent mixing of flocks during the alpine summer grazing must be considered an important risk factor for the spread of resistant nematodes to a large number of farms.

\section{Background}

Transhumance, the seasonal movement of livestock between mountain and lowland pastures, is a common form of pasturing in alpine areas. There are only few studies investigating the influence of this form of pasturing on infections with gastrointestinal nematodes (GIN) in sheep and on the development of anthelmintic resistance (AR), and GIN-related problems are barely characterized in this management system. Nevertheless, there are indications that common characteristics of mountain farming might promote the development of AR [1]. As GIN infections of small ruminants significantly affect animal health and thus farm profitability [2-5], widespread AR could seriously impair the current form of alpine sheep farming. Trichostrongyloids are the most prevalent nematodes of sheep, with Trichostrongylus colubriformis, Haemonchus contortus and Teladorsagia circumcincta amongst the most important. Infection with these parasites can result in reduced productivity of animals through poor weight gain, weight loss, reduced wool and milk production as well as weakness or ill-thrift [6-8]. Infection may also result in sudden death, especially when $H$. contortus is involved, as this haematophagous species is particularly pathogenic $[9,10]$.

Recommendations for best practice control of GIN underwent significant changes during the last decades worldwide. Since the introduction of broad-spectrum anthelmintics with good tolerability, control measures relied heavily on frequent application of chemical anthelmintics to the whole flock [11]. This has resulted in the selection for AR in nematodes against the main groups of anthelmintics, the benzimidazoles (BZs), the imidazothiazoles/tetrahydropyrimidines and the macrocylic lactones (MLs) and across multiple GIN species [12-14]. Currently, AR against BZs is the most common form, but the prevalence of multi-drug resistance is increasing [15-17]. New anthelmintics such as derquantel and monepantel have been developed, however, resistance against monepantel has already been described only two years after its introduction [18]. Consequently, the rapid development and spread of AR makes modern parasite management increasingly challenging $[4,19,20]$.

There is consensus that constant monitoring of the occurence of AR is required to maintain anthelmintic efficacy, as the early detection of AR is necessary for timely adjustment of parasite management measures, either in terms of treatment timing, product choice or both [8, 21].

For the detection of AR, the faecal egg count reduction test (FECRT) is the most commonly used method [22]. This in vivo test has the advantage of being applicable to all anthelmintic drug classes. However, it is labour intensive and only detects resistance if the level of genetically resistant individuals in the population is relatively high, above $25 \%$ [23]. In addition, the egg hatch test (EHT) or the larval development test are in vitro tests which have been standardised for several anthelmintics, but are also labour-intensive, and the EHT also does not detect low resistance levels [2325].

By contrast, molecular tests have very high sensitivity and specificity for the early detection of non-synonymous single nucleotide polymorphisms (SNPs), which are useful genetic markers for resistance [24, 25]. Knowledge of the role of these SNPs and other genetic markers is only sufficiently characterized for BZs, so BZs are currently the only drug class where a SNP analysis can indicate a resistant phenotype. In BZ-susceptible nematodes, BZs bind specifically and with high affinity to the nematode isotype- $1 \beta$-tubulin and prevent polymerisation of tubulin dimers into microtubules. Impaired microtubule function results in a reduced glucose uptake and protein secretion [26, 27]. In resistant nematodes, mutations in the isotype $1 \beta$-tubulin gene cause structural changes in the $\beta$-tubulin through amino acid changes that prevent BZs from binding [28]. These structural changes are associated with certain SNPs [29]. A SNP at codon 200 of the isotype 1 beta-tubulin gene which substitutes tyrosine (Tyr) for phenylalanine (Phe) (TTC>TAC) has been demonstrated in resistant isolates of $H$. contortus, T. colubriformis and T. circumcincta in sheep and is the most common SNP associated with BZ resistance [30, 31]. In addition, SNPs at two codons 167 and 198 (F167Y: TTC->TAC; E198A: GAG>GCG; E198L: GAG->TTG) have also been correlated with BZ resistance but occurred in lower frequency [32-34]. Although not all cases of 
resistance can be explained by the presence of these SNPs, their frequency in a population is able to explain the vast majority of reported cases of $\mathrm{BZ}$ resistance. There is a high correlation between the percentage of resistance alleles and a reduced FECR or increased EC ${ }_{50}$ in the EHT. However, screening for these SNPs is currently considered to be the most sensitive, robust and effective approach to screen field samples for the presence of BZ resistance [25, 35-37]. Different molecular assays for the detection of SNPs have been developed. Pyrosequencing is amongst the most commonly used [24,38]. For Austria, only very limited information is currently available on the status of AR in sheep nematodes [39]. Since knowledge about the efficacy of anthelmintic drugs is essential for the surveillance of AR development, we aimed to obtain data on BZ resistance in alpine regions of Austria, where grazing livestock, including sheep, is an integral part of agriculture.

The study presented here is part of a project on the surveillance of animal health in transhumance of sheep [40, 41]. As multi-drug AR is increasingly reported worldwide, it was one aim of the project to evaluate the efficacy for the most common anthelmintic drug classes. Due to the fact that no molecular markers for ML resistance are available, efficacy of moxidectin was evaluated by a FECRT and was shown to be reduced in vivo with one out of 16 farms showing resistance (egg count reduction of 93\%) and two farms with suspected resistance (LCL below $90 \%$ ) [40], stressing the importance of frequent AR monitoring. Using the material collected during the FECRT before treatment, the distribution and prevalence of BZ resistant genotypes in sheep from alpine transhumance flocks was assessed in the present study by pyrosequencing to provide additional information on the drug sensitivity of the nematodes infecting the examined sheep population.

\section{Results}

Larval pools from the different farms contained 500 to 61,600 larvae (Table 1). Percentages of H. contortus, T. circumcincta and T. colubriformis in pooled larval samples were between 0 and $48 \%$, between 2 and $22 \%$ and between 14 and $67 \%$, respectively (Table 1). Bunostomum, Cooperia, Chabertia and Oesophagostomum were also identified in pooled samples, at low prevalence. Detailed information about morphological differentiation of larvae is given in Schoiswohl et al. [41].

Codon 167 was successfully analysed in T. colubriformis and T. circumcincta in nine and ten farm populations respectively. Codons 198 and 200 were analysed in $\mathrm{H}$. contortus, T. colubriformis and T. circumcincta from ten, nine and nine of the 16 farm populations, respectively. Data for all five SNPs was obtained from two farms. Missing data was due to failure to produce PCR amplicon for pyrosequencing analysis (detailed in Table 1 as 'n.a.') or where insufficient DNA was available to run pyrosequencing assays for all SNPs of interest (detailed in Table 1 as 'n.d.').

The F200Y exchange was identified in all ten of the $H$. contortus populations tested; mean frequency of resistance alleles $91.9 \pm 3.7 \%$ (mean \pm SEM), range $49-100 \%$. In T. circumcincta, F200Y was identified in eight of nine populations analysed at a mean resistance allele frequency of 32.4 $\pm 6.8 \%$, range $0-66 \%$. No resistance alleles were observed at codon 167 of $T$. circumcincta in any of the populations analysed. The F200Y exchange was identified in all nine T. colubriformis populations tested; mean resistance allele frequency $94.2 \pm 2.9 \%$ (range $77-100 \%$ ), F167Y was identified in five of the nine populations tested; mean resistance allele frequency $7.1 \pm 2.9 \%$ (range $0-23 \%$ ) (Table 1 ). Results for codon 198 for all three species revealed no BZ resistance-associated alleles (frequencies below the technical background threshold of $5 \%$ ).

Farm structure and deworming.practices

Eight farms were full-time farms and seven were sideline enterprises (small-holder farms) (Table 1).

For 14/16 farms, information on deworming frequencies was available (Table 1). Seven farms used dewormers two times a year (in spring and autumn); the other seven farms used dewormers only once a year in spring.

For three farms, a reduced efficacy of moxidectin had already been observed [40]. No visible or significant difference on the percentage of resistance alleles was observed between farms for any of these variables.

\section{Discussion}

This is the first study evaluating for the presence of resistance alleles in ovine trichostrongyloids in Austria, focusing on sheep flocks within a transhumance management system. No FECRT could be performed because after several reports of treatment failure with BZs from attending veterinarians, farmers were not willing to use BZs to deworm their sheep. Consequently, all study animals were treated with moxidectin. The combination of FECRT for ML and molecular tests for BZs allowed estimation of resistance status regarding both drug classes in parallel. While it may be argued that the SNP-analysis is only an indirect diagnosis of resistance, there is convincing evidence available that the percentage of resistance alleles containing the exchanges F167Y, E198A or F200Y strongly correlates with the results of the FECRT and/or the EHT [24, 35, 37, 42, 43] while susceptible populations have very low levels of these resistance alleles. We also want to highlight that FECRT and EHT can even lead to inconclusive results in field populations with mixed infections [44]. Thus, by analysing specifically a single species, molecular analyses can overcome the limitations of in vivo and in vitro tests with mixed field samples.

Although all three SNPs have been reported to be associated with AR to the benzimidazoles, codon 200 remains the most prevalent and arguably the most important [25]. 
The F200Y exchange was found to be highly prevalent in H. contortus and T. colubriformis on the tested farms. T. circumcincta populations generally had lower F200Y allele frequencies, greater than $40 \%$ in five of the nine populations tested. A recent study identified the F200Y exchange at frequencies up to $13 \%$ in benzimidazole-susceptible strains of T. circumcincta, while resistant strains had allele frequencies above $60 \%$ [43]. This suggests that phenotypic benzimidazole resistance could be possible in some of the $T$. circumcincta populations tested within this study. The interaction between the F200Y and F167Y polymorphisms is not fully understood however, it has been suggested for T. circumcincta that F200Y mutation may predominate initially with the frequency of F167Y increasing with phenotypic resistance [45]. From the results presented, it could be hypothesised that BZ-resistance may be at an advanced stage in T. colubriformis in the region tested. Unfortunately, due to limited sample material, we were not able to perfom the SNP analysis on codon 167 (F200Y) of Haemonchus contortus although this SNP remains an important polymorphism in other regions of the world [24, 25]. However, the nearly complete manifestation of F200Y in the Haemonchus-samples suggests a high prevalence of clinically relevant BZ resistance.

Thus, it can be concluded that a high percentage of BZ resistant $H$. contortus and T.colubriformis are present in sheep in this region of Austria, while the frequency of resistant T. circumcincta remains moderate. This also supports anecdotal reports of poor efficacy of BZs in sheep in the investigated area. When compared to recent data [25], the frequency of resistance alleles of $H$. contortus in Austria is amongst the highest in Europe. This may be due to a long-standing "dose and move" practice on many Austrian farms practicing transhumance. Mutations leading to AR can arise due to the very large worm population sizes and be rapidly enriched due to strong selection by frequent strategic treatments in local nematode populations [34].

Similar high levels of BZ resistance were observed in goats in the alpine region of Italy $[1,46]$ supporting the assumption that resistance alleles associated with AR were spread through the introduction of resistant strains via animal movement and communal high altitude grazing. Dose and move strategies and animal movement are also common in Styria and Salzburg [41] and might be an important driving factor for the spread of AR on all farms investigated. In addition, strategies to maintain a refugium of anthelmintic-susceptible parasites, known to reduce the rate of development of anthelmintic resistance in GIN [11], may be especially difficult to implement when animals from different farms and management strategies are herded together on communal pastures. The deworming frequency in the study populations was low (1-2 treatments per year), but the deworming of all animals in spring before they are turned out to the mountain pastures clearly reduces the refugium for susceptible worms.

Haemonchus sp. are sensitive to cold weather [47] , and few Haemonchus larvae will survive the harsh conditions of the alpine winter. Consequently, Haemonchus overwinters largely in hypobiosis within the host, which accounts for the high prevalence observed in some regions with northern boreal/continental climate $[25,35,47,48]$. When all animals are treated before winter turn-in, Haemonchus encounters a significant bottleneck for survival [49], which increases the selective advantage for resistant worms that overwinter in their host and survive spring treatment, quickly increasing the proportion of resistant individuals on summer pastures.

Considering the present results in combination with the high fecundity of Haemonchus [47], there is considerable concern that the population of BZ resistant Haemonchus in Austria may expand further in size and geographic range e.g. through treatment errors, animal movement and/or the spread by wildlife hosts [50]. Indeed, Haemonchus increased in relation to other trichostrongyloids in faecal cultures examined during the course of the grazing season [41]. This trend was independent of BZ treatment as the sheep involved in the study were only treated with moxidectin during the investigated time period. It should, however, be mentioned that also macrocyclic lactone treatment might select for the variants F200Y and F167Y of Haemonchus [51].

One of the most popular strategies to slow the rate of development of AR is targeted selective treatment [20]. This leaves selected animals untreated. Untreated animals will then shed eggs of worms that were not exposed to anthelmintics, so presumably susceptible to the AH. These eggs of untreated animals will dilute eggs produced by any resistant worms which survived treatment within treated animals, and thus ameliorate the strong effects of drug selection by maintaining susceptible parasites in refugia [11, 20,47]. However, this strategy requires that a sufficient proportion of alleles associated with a susceptible phenotype are present within the population. The results of the present study suggest a lack of susceptibility-associated alleles at codon 200 in the $H$. contortus populations. Therefore, leaving some sheep untreated would not be effective in reducing resistance allele frequencies and thus BZ resistance, unless a susceptible population of $H$. contortus was introduced [52]. Ideally, susceptibility of this introduced worm population should be tested at the genetic level. It has also to be considered that adding only $H$. contortus larvae into the population would increase the relative prevalence of this highly pathogenic species in the overall trichostrongyloid population potentially resulting in greater production losses, so until more evidence of this strategy is provided we would not recommend this approach. Nevertheless, selective treatment is still considered to be an appropriate strategy for the region under investigation in this study, especially for slowing down selection of AR against other anthelmintic classes.

The fact that the prevalence of BZ resistance genotypes was very high in three flocks where ML resistance was also observed shows that multidrug-resistant trichostrongyloid nematodes of sheep can also occur in extensive management systems such as transhumance in alpine Austria. If no alternative strategies are implemented in the near future, it must be expected that AR will be widespread and irreversible [53]. Information and instruction to farmers by veterinarians is strongly recommended, especially since a considerable part of the Austrian sheep population is kept by farmers with sideline enterprises or hobby farmers who may not have sufficent knowledge and experience with novel antiparasitic management. 
In the longer term, economical and sustainable management of grazing livestock will likely depend on three main strategies: (1) rational use of licensed anthelmintic drugs to slow down the selection of resistant populations using approaches such as targeted selective treatment [20], (2) the development of new effective anthelmintic drug classes and (3) the improvement of strategies that do not depend on the administration of anthelmintics [54]. For the latter there are a number of approaches such as vaccination, breeding and grazing management. Vaccination against haemonchosis is a promising development for farms heavily afflicted by this worm [55-57]. The first commercial vaccine, Barbevax ${ }^{\circledR}$, has been evaluated in several countries and is available in Australia since 2014 [58]. However, the high frequency of vaccination required in the first two years would be very difficult to implement under transhumance farming management. Animals kept in transhumance are not easely accessible and this will intensify the work load for farmers tremendously. Breeding sheep that are resilient or resistant to worm infections is another feasible strategy [59] and appropriate grazing management is still the cornerstone of non-chemical strategies [47, 60].

\section{Conclusion}

In agreement with recent studies from many geographical regions, a high frequency of AR genotypes in nematodes from Austrian sheep kept in transhumance husbandary systems was detected. Management and climate factors in mountain regions might increase the rate of selection for resistant worms by reducing refugia on pasture. Furthermore, the joint grazing of animals from many different farms promotes gene flow and the development of AR. In order to preserve productivity of sheep farming in this area in future, there is an urgent need to implement alternative strategies in transhumance that do not rely so much on the use of anthelmintics as current management practices and that help to maintain refugia in alpine grazing systems.

\section{Methods}

\section{Collection of field samples}

The collection of field samples was published previously [40, 41]. Briefly, 243 adult animals (ewes) from 16 farms (6 -31 animals/farm) in the federal states of Styria $(n=13)$ and Salzburg $(n=3)$, Austria, were examined. These sheep were stabled over winter and brought to pens near to the farms in spring before they were moved to alpine pastures together with sheep from other farms. Faecal samples used for this study were taken in March 2015, shortly before turnout to communal pastures. The farms that were included were attended by the the veterinary animal health service advising the best strategy for anthelmintic treatment. All animals were treated with moxidectin because it was considered to be the most effective anthelmintic drug. The history of anthelmintic drug application was documented in as much detail as possible, as described in [41].

\section{$\underline{\text { Larval cultures }}$}

For each farm, one pooled sample of third stage larvae was obtained by faecal culture and morphologically speciated as described previously [61]. Larvae where exsheathed in an aqueous solution containing $5 \%(\mathrm{v} / \mathrm{v})$ sodium hypochlorite, washed three times in distilled water followed by centrifugation at $150 \mathrm{rpm}$ for 10 minutes and maintained in $70 \%(\mathrm{v} / \mathrm{v})$ ethanol at $4{ }^{\circ} \mathrm{C}$ until further processing.

\section{DNA extraction}

Before extraction, samples were allowed to sit for 15 minutes at $35^{\circ} \mathrm{C}$ to allow ethanol to evaporate. Then, DNA was extracted from whole pools of 500 to 61,600 larvae (Table 1) using the NucleoSpin ${ }^{\circledR}$ Soil Kit (Macherey-Nagel, Düren, Germany) following the manufacturer's instructions, using buffer SL1 without enhancer. The DNA was eluted in $100 \mu \mathrm{l}$ of the elusion buffer (SE) and the DNA samples were stored at -20 ${ }^{\circ} \mathrm{C}$ until use.

\section{Determination of SNP frequencies}

Pyrosequencing assays for the detection SNPs leading to the exchanges E198A and F200Y in both H. contortus and T. circumcincta and F167Y in T. circumcincta were carried out as previously described [24,62]. Primer information is given in Table 2.

The PCR was conducted in $50 \mu \mathrm{l}$ reaction volumes using the NovaTaq ${ }^{\mathrm{TM}}$ Hot Start PCR Master Mix Kit (Merck Millipore, Darmstadt, Germany). Each reaction contained $25 \mu \mathrm{l}$ mastermix with a final $\mathrm{MgCl}_{2}$ concentration of $1.5 \mathrm{mM}, 0.2 \mu \mathrm{M}$ biotinylated primer, $0.4 \mu \mathrm{M}$ of the non-biotinylated primer and $4 \mu \mathrm{l}$ of template DNA. Using an Eppendorf MasterCycler Pro ${ }^{\circledR}$ (Eppendorf, Hamburg, Germany), reactions were incubated at $95{ }^{\circ} \mathrm{C}$ for 7 min followed by 45 cycles of $94^{\circ} \mathrm{C}$ for $30 \mathrm{~s}, 58^{\circ} \mathrm{C}$ ( T. circumcincta) or $53^{\circ} \mathrm{C}\left(\mathrm{H}\right.$. contortus) for $30 \mathrm{~s}, 72{ }^{\circ} \mathrm{C}$ for $45 \mathrm{~s}$ and a final hold at $72{ }^{\circ} \mathrm{C}$ for $10 \mathrm{~min}$. Five microliters of each PCR product were run on a $2 \%$ agarose gel, stained with Midori Green ${ }^{\circledR}$ DNA Stain (Nippon Genetics; Biozym, Oldendorf, Germany), subjected to vertical electrophoresis at a constant voltage of $120 \mathrm{~V}$ and scanned under UV light in a LumiBIS ${ }^{\circledR}$ (DNR Bio-Imaging System, Neve Yamin, Israel) to verify successful amplification. $45 \mu \mathrm{l}$ of biotinylated PCR product were then used in each pyrosequencing assay.

Pyrosequencing reactions were performed targeting SNPs 167 and 198/200 in T. circumcincta and SNPs 198/200 in H. contortus using a PyroMark ID Pyrosequencer (Biotage, Uppsala, Sweden) following the manufacturer's recommended protocol. 
T. colubriformis assays were performed as described by Ramünke et. al. [25]. In brief, PCRs were conducted using Phusion ${ }^{\circledR}$ Hot-Start II High Fidelity DNA polymerase (Thermo Scientific, St. Leon-Rot, Germany). Reactions (50 $\mu$ l) contained 200 mM dNTPs (Thermo Scientific), 250 nM of each primer, $1 \mathrm{U}$ Phusion ${ }^{\circledR}$ polymerase and $4 \mu \mathrm{l}$ genomic DNA. After an initial denaturation at $98^{\circ} \mathrm{C}$ for $30 \mathrm{~s}, 40$ cycles of denaturation at $98^{\circ} \mathrm{C}$ for $10 \mathrm{~s}$, annealing at a primer-pair specific temperature (Table 2) for $30 \mathrm{~s}$ and elongation at $72{ }^{\circ} \mathrm{C}$ for $30 \mathrm{~s}$ followed were performed before a final elongation at $72{ }^{\circ} \mathrm{C}$ for $10 \mathrm{~min}$. PCRs were controlled by electrophoresis in $1.5 \%$ agarose gels stained with GR Green (Ozyme, Saint Cyr L'Ecole, France). Pyrosequencing assays were performed as previously described [63] using a PyroMark Q24 instrument and $22-45 \mu \mathrm{l}$ of the PCR product.

For $T$. circumcincta and $H$. contortus, positive controls representing genomic DNA extracted from susceptible and resistant individual adults from each species were included in each assay. Assays for T. colubriformis were evaluated in separate runs using artificial mixtures of plasmid DNA containing the different SNPs as template. The frequencies of the resistance allele with values equal to or lower than $5 \%$ were considered as technical background and, therefore, not considered as resistant [37].

\section{Declarations}

\section{Ethics approval and consent to participate}

This investigation was approved by the institutional ethics and animal welfare committee of the Vetmeduni Vienna in accordance with good scientific practice guidelines and national legislation. Written consent to take samples from the animals was obtained from all the animal's owners.

Sampling and larval examinations were previously published [40, 41].

\section{Consent to publish}

Not applicable.

\section{Availability of data and materials}

The datasets generated and analysed during the current study are available from the correspoinding author on reasonable request.

\section{Competing interests}

The authors state that thery have no competing interests. KB is employed by the Animal Health Service Styria. JK and PS are associate editors of BMC Veterinary research.

\section{Funding}

This study was partially financed by the Animal Health Service Styria (TGD). KB is employed by the TGD. KB helped in the field-work by recruting participating farms that are all supervised and consulted by the TGD. He also contributed to the drafting of the manuscript. JK is employed at the FU Berlin and pyrosequencing of Trichostrongylus was partialy funded by internal funds of FU Berlin. Funding bodies except of the authors had no influence on study design, interpretation of data and the decision to publish.

\section{Authors'Contributions}

$\mathrm{BH}, \mathrm{JS}, \mathrm{RKF}$ and AJ planned, designed and initiated the study, JS and KB performed the field work. LM, JK, PS, BH, WWP, VJA performed the laboratory work and interpreted the data, $\mathrm{BH}$ and JS wrote the manuscript and revised it. All authors contributed to the critical revision and approved the final version of the manuscript.

\section{Acknowledgements}

The authors thank the participating farms.

This article is based in part upon work from COST Action COMBAR CA16230, supported by COST (European Cooperation in Science and Technology).

\section{Abbreviations}

AR: Anthelmintic resistance; BZ: Benzimidazole anthelmintics; GIN: Gastrointestinal nematodes; SNP: Single nucleotide polymorphism; ML: macrocyclic lactones; FECRT: faecal egg count reduction test; EHT: egg hatch test

\section{References}


1. Lambertz C, Poulopoulou I, Wuthijaree K, Gauly M. Anthelmintic efficacy against gastrointestinal nematodes in goats raised under mountain farming conditions in northern Italy. BMC Vet Res. 2019;15:216. doi:10.1186/s12917-019-1968-8.

2. Albers GAA, Gray GD, Le JLF, Piper LR, Barger IA, Barker JSF. The effect of Haemonchus contortus on liveweight gain and wool growth in young merino sheep. Aust J Agric Res. 1989;40:419. doi:10.1071/AR9890419.

3. Cringoli G, Veneziano V, Jackson F, Vercruysse J, Greer AW, Fedele V, et al. Effects of strategic anthelmintic treatments on the milk production of dairy sheep naturally infected by gastrointestinal strongyles. Vet Parasitol. 2008;156:340-5.

4. Charlier J, van der Voort M, Kenyon F, Skuce P, Vercruysse J. Chasing helminths and their economic impact on farmed ruminants. Trends Parasitol. 2014;30:361-7.

5. Mavrot F, Hertzberg H, Torgerson P. Effect of gastro-intestinal nematode infection on sheep performance: a systematic review and metaanalysis. Parasit Vectors. 2015;8:187. doi:10.1186/s13071-015-1164-z.

6. Symons LEA, Steel JW, Jones WO. Effects of level of larval intake on the productivity and physiological and metabolic responses of lambs infected with Ostertagia circumcincta. Aust J Agric Res. 1981;32:139.

7. Cringoli G, Veneziano V, Pennacchio S, Mezzino L, Santaniello M, Schioppi M, et al. Economic efficacy of anthelmintic treatments in dairy sheep naturally infected by gastrointestinal strongyles. Parassitologia. 2007;49:201-7.

8. Roeber F, Jex AR, Gasser RB. Impact of gastrointestinal parasitic nematodes of sheep, and the role of advanced molecular tools for exploring epidemiology and drug resistance - an Australian perspective. Parasit Vectors. 2013;6:1363. doi:10.1186/1756-3305-6-153.

9. Cobon DH, O'Sullivan BM. Effect of Haemonchus contortus on productivity of ewes, lambs and weaners in a semi-arid environment. J Agric Sci. 1992;118:245-8.

10. Emery DL, Hunt PW, Le Jambre LF. Haemonchus contortus: the then and now, and where to from here? Int J Parasitol. 2016;46:755-69.

11. van Wyk JA. Refugia-overlooked as perhaps the most potent factor concerning the development of anthelmintic resistance. Onderstepoort $J$ Vet Res. 2001;68:55-67.

12. Waller PJ. The development of anthelmintic resistance in ruminant livestock. Acta Trop. 1994;56:233-43.

13. Falzon LC, O'Neill TJ, Menzies PI, Peregrine AS, Jones-Bitton A, vanLeeuwen J, Mederos A. A systematic review and meta-analysis of factors associated with anthelmintic resistance in sheep. Prev Vet Med. 2014;117:388-402.

14. Kotze AC, Prichard RK. Anthelmintic Resistance in Haemonchus contortus: History, Mechanisms and Diagnosis. Adv Parasitol. 2016;93:397428.

15. Ploeger HW, Everts RR. Alarming levels of anthelmintic resistance against gastrointestinal nematodes in sheep in the Netherlands. Vet Parasitol. 2018;262:11-5.

16. Papadopoulos E, Gallidis E, Ptochos S. Anthelmintic resistance in sheep in Europe: a selected review. Vet Parasitol. 2012;189:85-8.

17. Sangster NC, Cowling A, Woodgate RG. Ten Events That Defined Anthelmintic Resistance Research. Trends Parasitol. 2018;34:553-63.

18. Sales N, Love S. Resistance of Haemonchus to monepantel and reduced efficacy of a derquantel / abamectin combination confirmed in sheep in NSW, Australia. Vet Parasitol. 2016;228:193-6.

19. Miller CM, Waghorn TS, Leathwick DM, Candy PM, Oliver A-MB, Watson TG. The production cost of anthelmintic resistance in lambs. Vet Parasitol. 2012;186:376-81.

20. Charlier J, Morgan ER, Rinaldi L, van Dijk J, Demeler J, Höglund J, et al. Practices to optimise gastrointestinal nematode control on sheep, goat and cattle farms in Europe using targeted (selective) treatments. Vet Rec. 2014;175:250-5.

21. Taylor MA. SCOPS and COWS-'worming it out of UK farmers'. Vet Parasitol. 2012;186:65-9.

22. Coles GC, Jackson F, Pomroy WE, Prichard RK, Samson-Himmelstjerna G von, Silvestre A, et al. The detection of anthelmintic resistance in nematodes of veterinary importance. Vet Parasitol. 2006;136:167-85.

23. Martin PJ, Anderson N, Jarrett RG. Detecting benzimidazole resistance with faecal egg count reduction tests and in vitro assays. Aust Vet J. 1989;66:236-40.

24. von Samson-Himmelstjerna G, Walsh TK, Donnan AA, Carrière S, Jackson F, Skuce PJ, et al. Molecular detection of benzimidazole resistance in Haemonchus contortus using real-time PCR and pyrosequencing. Parasitology. 2009;136:349-58.

25. Ramünke S, Melville L, Rinaldi L, Hertzberg H, Waal T de, Samson-Himmelstjerna G von, et al. Benzimidazole resistance survey for Haemonchus, Teladorsagia and Trichostrongylus in three European countries using pyrosequencing including the development of new assays for Trichostrongylus. Int J Parasitol Drugs Drug Resist. 2016;6:230-40.

26. Lacey $\mathrm{E}$. The role of the cytoskeletal protein, tubulin, in the mode of action and mechanism of drug resistance to benzimidazoles. Int $\mathrm{J}$ Parasitol. 1988;18:885-936.

27. Prichard R. Anthelmintic resistance. Vet Parasitol. 1994;54:259-68.

28. Lacey E, Gill JH. Biochemistry of benzimidazole resistance. Acta Trop. 1994;56:245-62. 
29. Kwa MS, Veenstra JG, Roos MH. Benzimidazole resistance in Haemonchus contortus is correlated with a conserved mutation at amino acid 200 in beta-tubulin isotype 1. Mol Biochem Parasitol. 1994;63:299-303.

30. Kwa MS, Veenstra JG, van Dijk M, Roos MH. Beta-tubulin genes from the parasitic nematode Haemonchus contortus modulate drug resistance in Caenorhabditis elegans. J Mol Biol. 1995;246:500-10.

31. von Samson-Himmelstjerna G, Blackhall WJ, McCarthy JS, Skuce PJ. Single nucleotide polymorphism (SNP) markers for benzimidazole resistance in veterinary nematodes. Parasitology. 2007;134:1077-86.

32. Prichard R. Genetic variability following selection of Haemonchus contortus with anthelmintics. Trends Parasitol. 2001;17:445-53.

33. Ghisi M, Kaminsky R, Mäser P. Phenotyping and genotyping of Haemonchus contortus isolates reveals a new putative candidate mutation for benzimidazole resistance in nematodes. Vet Parasitol. 2007;144:313-20.

34. Redman E, Whitelaw F, Tait A, Burgess C, Bartley Y, Skuce PJ, et al. The emergence of resistance to the benzimidazole anthelmintics in parasitic nematodes of livestock is characterised by multiple independent hard and soft selective sweeps. PLoS Negl Trop Dis. 2015;9:e0003494. doi:10.1371/journal.pntd.0003494.

35. Höglund J, Gustafsson K, Ljungström B-L, Engström A, Donnan A, Skuce P. Anthelmintic resistance in Swedish sheep flocks based on a comparison of the results from the faecal egg count reduction test and resistant allele frequencies of the beta-tubulin gene. Vet Parasitol. 2009;161:60-8.

36. Barrère V, Keller K, Samson-Himmelstjerna G von, Prichard RK. Efficiency of a genetic test to detect benzimidazole resistant Haemonchus contortus nematodes in sheep farms in Quebec, Canada. Parasitol Int. 2013;62:464-70.

37. Esteban-Ballesteros M, Rojo-Vázquez FA, Skuce PJ, Melville L, González-Lanza C, Martínez-Valladares M. Quantification of resistant alleles in the $\beta$-tubulin gene of field strains of gastrointestinal nematodes and their relation with the faecal egg count reduction test. BMC Vet Res. 2017;13:71. doi:10.1186/s12917-017-0992-9.

38. Royo JL, Hidalgo M, Ruiz A. Pyrosequencing protocol using a universal biotinylated primer for mutation detection and SNP genotyping. Nat Protoc. 2007;2:1734-9.

39. Feichtenschlager C, Hinney B, Klose S, Tichy A, Tix A, Strobl L, Krametter-Frötscher R. The occurrence of helminths in small ruminants in styria (Austria) with special attention to the effi cacy of benzimidazoles and macrocyclic lactones. Wien Tierärztl Monatsschr. 2014;101: 251-262.

40. Schoiswohl J, Hinney B, Tichy A, Bauer K, Joachim A, Krametter-Frötscher R. Suspected resistance against moxidectin in sheep strongylid nematodes in Austria. J Pharmacy Pharmacol. 2017. doi:10.17265/2328-2150/2017.03.001.

41. Schoiswohl J, Joachim A, Hinney B, Tichy A, Bauer K, Stanitznig A, Krametter-Froetscher R. Influence of communal alpine pasturing in Styria, Austria, on the development of gastrointestinal strongylid infections over the grazing season in sheep - a pilot study. Berl Münch Tierärztl Wochenschr. 2017;130:494-500.

42. Yilmaz E, Ramünke S, Demeler J, Krücken J. Comparison of constitutive and thiabendazole-induced expression of five cytochrome P450 genes in fourth-stage larvae of Haemonchus contortus isolates with different drug susceptibility identifies one gene with high constitutive expression in a multi-resistant isolate. Int J Parasitol Drugs Drug Resist. 2017;7:362-9.

43. Sargison ND, MacLeay M, Morrison AA, Bartley DJ, Evans M, Chaudhry U. Development of amplicon sequencing for the analysis of benzimidazole resistance allele frequencies in field populations of gastrointestinal nematodes. Int J Parasitol Drugs Drug Resist. 2019;10:92100.

44. Mohammedsalih KM, Krücken J, Khalafalla A, Bashar A, Juma F-R, Abakar A, et al. New codon 198 -tubulin polymorphisms in highly benzimidazole resistant Haemonchus contortus from goats in three different states in Sudan. Parasit Vectors. 2020;13:114.

45. Kotze AC, Cowling K, Bagnall NH, Hines BM, Ruffell AP, Hunt PW, Coleman GT. Relative level of thiabendazole resistance associated with the E198A and F200Y SNPs in larvae of a multi-drug resistant isolate of Haemonchus contortus. Int J Parasitol Drugs Drug Resist. 2012;2:92-7.

46. Lambertz C, Poulopoulou I, Wuthijaree K, Gauly M. Anthelmintic resistance in gastrointestinal nematodes in sheep raised under mountain farming conditions in Northern Italy. Vet Rec Open. 2019;6:e000332. doi:10.1136/vetreco-2018-000332.

47. Besier RB, Kahn LP, Sargison ND, van Wyk JA. Diagnosis, treatment and management of Haemonchus contortus in small ruminants. Adv Parasitol. 2016;93:181-238.

48. Waller PJ, Rudby-Martin L, Ljungström BL, Rydzik A. The epidemiology of abomasal nematodes of sheep in Sweden, with particular reference to over-winter survival strategies. Vet Parasitol. 2004;122:207-20.

49. Gilleard JS. Haemonchus contortus as a paradigm and model to study anthelmintic drug resistance. Parasitology. 2013;140:1506-22.

50. Chintoan-Uta C, Morgan ER, Skuce PJ, Coles GC. Wild deer as potential vectors of anthelmintic-resistant abomasal nematodes between cattle and sheep farms. Proceedings of the Royal Society B: Biological Sciences 2014. doi:10.1098/rspb.2013.2985.

51. Lourdes Mottier M de, Prichard RK. Genetic analysis of a relationship between macrocyclic lactone and benzimidazole anthelmintic selection on Haemonchus contortus. Pharmacogenet Genomics. 2008;18:129-40.

52. Bird J, Shulaw WP, Pope WF, Bremer CA. Control of anthelmintic resistant endoparasites in a commercial sheep flock through parasite community replacement. Vet Parasitol. 2001;97:219-25.

Page $8 / 10$ 
53. Borgsteede FH, Duyn SP. Lack of reversion of a benzimidazole resistant strain of Haemonchus contortus after six years of levamisole usage. Res Vet Sci. 1989;47:270-2.

54. Hoste H, Torres-Acosta JFJ. Non chemical control of helminths in ruminants: adapting solutions for changing worms in a changing world. Vet Parasitol. 2011;180:144-54.

55. Besier RB. Refugia-based strategies for sustainable worm control: factors affecting the acceptability to sheep and goat owners. Vet Parasitol. 2012;186:2-9.

56. Bassetto CC, Amarante AFT. Vaccination of sheep and cattle against haemonchosis. J Helminthol. 2015;89:517-25.

57. Nisbet AJ, Meeusen EN, González JF, Piedrafita DM. Immunity to Haemonchus contortus and Vaccine Development. Adv Parasitol. 2016;93:353-96.

58. Bassetto CC, Almeida FA, Newlands GFJ, Smith WD, Castilhos AM, Fernandes S, et al. Trials with the Haemonchus vaccine, Barbervax ${ }^{\circledR}$, in ewes and lambs in a tropical environment: Nutrient supplementation improves protection in periparturient ewes. Vet Parasitol. 2018;264:52-7.

59. Bishop SC. A consideration of resistance and tolerance for ruminant nematode infections. Front Genet. 2012;3:168. doi:10.3389/fgene.2012.00168.

60. Learmount J, Stephens N, Boughtflower V, Barrecheguren A, Rickell K. The development of anthelmintic resistance with best practice control of nematodes on commercial sheep farms in the UK. Vet Parasitol. 2016;229:9-14.

61. van Wyk JA, Mayhew E. Morphological identification of parasitic nematode infective larvae of small ruminants and cattle: A practical lab guide. Onderstepoort J Vet Res 2013. doi:10.4102/ojvr.v80i1.539.

62. Skuce P, Stenhouse L, Jackson F, Hypsa V, Gilleard J. Benzimidazole resistance allele haplotype diversity in United Kingdom isolates of Teladorsagia circumcincta supports a hypothesis of multiple origins of resistance by recurrent mutation. Int J Parasitol. 2010;40:1247-55.

63. Demeler J, Krüger N, Krücken J, Heyden VC von der, Ramünke S, Küttler U, et al. Phylogenetic characterization of $\beta$-tubulins and development of pyrosequencing assays for benzimidazole resistance in cattle nematodes. PLoS ONE. 2013;8:e70212. doi:10.1371/journal.pone.0070212.

\section{Tables}

Table 1: Frequencies of alleles containing the F167Y, E198A and F200Y exchanges correlating with benzimidazole resistance for Haemonchus contortus, Teladorsagia circumcincta and Trichostrongylus colubriformis. $(<5 \%=$ below background threshold)

\begin{tabular}{|c|c|c|c|c|c|c|c|c|c|}
\hline $\mathrm{rm}$ & $\underset{\text { larvae }}{\mathbf{N}}$ & $\begin{array}{l}\% \text { of trichostr } \\
\text { stage larval s }\end{array}$ & $\begin{array}{l}\text { ongyloid speci } \\
\text { amples used fo }\end{array}$ & $\begin{array}{l}\text { s in pooled third } \\
\text { pyrosequencing }\end{array}$ & $\begin{array}{c}H . \\
\text { contortus }\end{array}$ & $\begin{array}{c}T . \\
\text { circumcincta }\end{array}$ & $\begin{array}{c}T . \\
\text { circumcincta }\end{array}$ & $\underset{\text { colubriformis }}{T .}$ & $\underset{\text { colubriformis }}{T .}$ \\
\hline & $\begin{array}{l}\text { pooled } \\
\text { samples }\end{array}$ & Haemonchus & Teladorsagia & Trichostrongylus & & & & & \\
\hline $\begin{array}{l}\mathrm{L} \\
\mathrm{T})^{*}\end{array}$ & 1566 & 4 & 7 & 32 & $49 ; 71^{\mathrm{a}}$ & n.a. & $<5$ & 100 & $<5$ \\
\hline $\begin{array}{l}2 \\
{[)^{* *}}\end{array}$ & 17600 & 48 & 2 & 36 & 96 & 66 & $<5$ & 99 & $<5$ \\
\hline $\begin{array}{l}3 \\
\mathrm{~T})^{*}\end{array}$ & 14400 & 42 & 12 & 36 & 93 & 31 & $<5$ & n.d. & n.d. \\
\hline $\begin{array}{l} \pm \\
{[)^{* *}}\end{array}$ & 4666 & 26 & 17 & 40 & 95 & n.a. & $<5$ & 77 & 23 \\
\hline$i^{*}$ & 1600 & 36 & 5 & 39 & 87 & 18 & n.a. & n.d. & n.d. \\
\hline ** & 500 & 0 & 8 & 66 & n.a. & $<5$ & $<5$ & n.d. & n.d. \\
\hline ** & 8500 & 30 & 12 & 39 & 98 & n.a. & n.a. & n.d. & n.d. \\
\hline$i^{*}$ & 61666 & 21 & 2 & 42 & n.a. & 48 & $<5$ & n.d. & n.d. \\
\hline$* *$ & 1666 & 1 & 6 & 67 & 99 & n.a. & n.a. & 97 & $<5$ \\
\hline $\begin{array}{l}0 \\
{[]^{* *}}\end{array}$ & 2000 & 39 & 8 & 50 & 100 & 11 & n.a. & 100 & $<5$ \\
\hline $1^{*}$ & 2666 & 14 & 2 & 14 & 94 & 40 & $<5$ & n.d. & n.d. \\
\hline $\begin{array}{l}2 \\
\text { (T) }\end{array}$ & 42666 & 16 & 8 & 53 & n.a. & 47 & $<5$ & 98 & 7 \\
\hline $\begin{array}{l}3 \\
{[)^{* *}}\end{array}$ & 2666 & 2 & 22 & 58 & $100 ; 94^{\mathrm{a}}$ & 31 & $<5$ & 95 & 9 \\
\hline $4^{*}$ & n.d. & 11 & 9 & 36 & n.a. & n.a. & n.a. & 82 & 19 \\
\hline $\begin{array}{c}5 \\
\Gamma)^{*}\end{array}$ & n.d. & 3 & 17 & 61 & n.a. & n.a. & $<5$ & 100 & 6 \\
\hline
\end{tabular}


n.d.: no data (no DNA left for analysis); n.a.: no amplicon generated; FT: full-time farms, all other farms were sideline enterprises (small-holder farms); *: indicates farms that used dewormers once a year; **: indicates farms that used dewormers

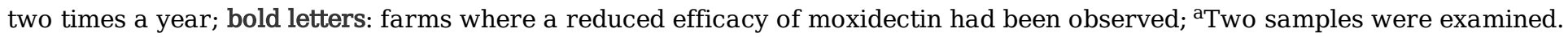

Table 2: Description of primers used

\begin{tabular}{|c|c|c|c|c|}
\hline $\begin{array}{l}\text { Targeted trichostrongyloid species; primer } \\
\text { name }\end{array}$ & Sequence $5^{\prime}$ to $3^{\prime}$ & $\begin{array}{l}\text { Size [base } \\
\text { pairs] }\end{array}$ & ${ }_{\left[{ }^{\circ} \mathrm{C}\right]}^{\mathrm{Tm}}$ & Reference \\
\hline \multicolumn{5}{|l|}{ Haemonchus contortus } \\
\hline HcPy2PCR For & GAC GCA TTC ACT TGG AGG AG & \multirow[t]{2}{*}{400} & \multirow[t]{2}{*}{53} & \multirow[t]{2}{*}{ [24] } \\
\hline HcPy2PCR Rev & Biotin-CAT AGG TTG GAT TTG TGA GTT & & & \\
\hline \multicolumn{5}{|l|}{ Teladorsagia circumcincta } \\
\hline F200Y_FOR & $\begin{array}{l}\text { Biotin- ACC TTA CAA TGC CAC TCT } \\
\text { TTC TG }\end{array}$ & \multirow[t]{2}{*}{100} & \multirow[t]{2}{*}{58} & \multirow[t]{4}{*}{ [62] } \\
\hline F200Y_REV & GCG GAA GCA GAT ATC GTA CAG & & & \\
\hline F167Y_FOR & GCA TTC TTT GGG AGG AGG TA & \multirow[t]{2}{*}{200} & \multirow[t]{2}{*}{58} & \\
\hline F167Y_REV & $\begin{array}{l}\text { Biotin-TGC ACC TCG AGA ACC TGT } \\
\text { ACA TA }\end{array}$ & & & \\
\hline \multicolumn{5}{|l|}{ Trichostrongylus colubriformis } \\
\hline FOR & TAC CCA GAT CGG ATT ATG TCT TC & & \multirow[t]{2}{*}{58} & \multirow[t]{2}{*}{ [25] } \\
\hline REV & $\begin{array}{l}\text { Biotin - GGC AAG TCG TGA CAC CAG } \\
\text { ACA }\end{array}$ & & & \\
\hline \multicolumn{5}{|l|}{ Pyrosequencing primer } \\
\hline Hc200PySeq1 (Haemonchus, Codon 200) & TAG AGA ACA CCG ATG AAA & \multirow{5}{*}{\multicolumn{2}{|c|}{ Not applicable }} & [24] \\
\hline $\begin{array}{l}\text { T. circ. F200Y_SEQ ( Teladorsagia, Codon } \\
\text { 200) }\end{array}$ & RGA GCY TCA TTA TCG ATR & & & [62] \\
\hline $\begin{array}{l}\text { T. circ. F167Y_SEQ (Teladorsagia, Codon } \\
\text { 167) }\end{array}$ & CGG ATA GAA TCA TGG CT & & & [62] \\
\hline T. colubriformis Codon 198_200 & GCA GTA CTC GTG TC & & & [25] \\
\hline T. colubriformis Codon 167 & CGG ATA GAA TCA TGG CT & & & \\
\hline
\end{tabular}

